\title{
Health Risk Assessment on Rural Drinking Water Safety -A Case Study in Rain City District of Ya'an City of Sichuan Province
}

\author{
Fuquan NI ${ }^{1,2}$, Guodong LIU ${ }^{2}$, Huazhun REN ${ }^{3}$, Shangchuan YANG ${ }^{1}$, Jian YE ${ }^{1}$, Xiuyuan LU ${ }^{1,2}$, Min YANG \\ ${ }^{1}$ College of Information \& Engineering, Sichuan Agricultural University, Ya'an, China \\ ${ }^{2}$ College of Water Resources \& Hydropower, Sichuan University, Chengdu, China \\ ${ }^{3}$ College of Hydrology \& Water Resources, Hohai University, Nanjing, China \\ E-mail: nfq1965@163.com \\ Received March 31, 2009; revised May 28, 2009; accepted May 31, 2009
}

\begin{abstract}
Taking Rain City District of Ya'an for example, this paper based on ComGIS (Component Object Model Geographic Information System) platform takes comprehensive and systematic detection on the exposure dose of chemical carcinogens and non-carcinogens from drinking water sources in this region and discusses health risk assessment of single factor and the whole health risk assessment. $\mathrm{As}, \mathrm{Hg}, \mathrm{Cr}, \mathrm{Pb}, \mathrm{Cd}$ and fluorides in some drinking water sources of Rain City District are analyzed according to Standards For Drinking Water Quality (GB5749-2006). A health risk assessment model called USEPA is also applied to drinking water health risk assessment and management countermeasure is proposed.

The results show that the greatest health risk for individual person per year is caused by $\mathrm{Cr}(\mathrm{VI})$. The health risk of carcinogens is much higher than that of non-carcinogens: the greatest risk value due to non-carcinogen pollutants is caused by fluoride $(\mathrm{F})$, achieving $1.05 \times 10^{-8} / \mathrm{a}$. The ranking of risk values due to non-carcinogen pollutants by drinking water is $\mathrm{Pb}>$ fluoride $(\mathrm{F})>\mathrm{Hg}$, within $\mathrm{Pb}$ accounting for $44.77 \%$, fluoride (F) accounting for $34.30 \%$ and $\mathrm{Hg}$ accounting for $20.92 \%$. The average individual carcinogenesis annual risk of $\mathrm{Cr}(\mathrm{VI})$ is the greatest, achieving $8.91 \times 10^{-4} / \mathrm{a}$. The ranking of risk value due to chemical carcinogen by rural drinking water of $\mathrm{Ya}^{\prime}$ an is $\mathrm{Cr}^{6+}>\mathrm{As}>\mathrm{Cd}$, within $\mathrm{Cr}^{6+}$ accounting for $91.12 \%$, As accounting for 5.89\% and $\mathrm{Cd}$ accounting for $3.00 \%$. Based on this, the strategy and measures of the health risk management are put forward.

This study has worked efficiently in practice. Compared with the same kind of methods which have been found, the paper has the outstanding results for the health risk assessment of the rural drinking water safety.
\end{abstract}

Keywords: Rural Drinking Water Safety, Health Risk Assessment, ComGIS, Ya'an

\section{Introduction}

At present, water safety and water environment health risk assessment is mainly focused on the polluted fields in certain areas, the drinking water of city, reuse of wastewater in city, groundwater, etc. The rural drinking water safety is being paid more and more attention.

The report from UN points out that there are $80 \%$ human diseases caused by unsafe drinking water in poor areas and about 25 thousand people died of unsafe drinking water every day. Besides, the report from World Health Organization (WHO) points out that there are
$1 / 3$ people living in the city of developing countries could not get safe drinking water in the world $[1,2]$.

In China, there are about 300 million rural residents have no safe water supply, so the drinking water safety is important. It is not only the problem of resources and environment, but also the strategic problem, which have influence on the national economy, sustainable development of society, as well as the harmony between water and human. The factors influencing rural drinking water are multitudinous, which have non-determinism and the spatial variability characteristics. Based on this, the paper coupled the ComGIS technology and the health risk as- 
sessment model together, carries out the spatial analysis and the system research of rural drinking water safety problem in typical mountainous region of Ya'an, Sichuan $[3,4]$.

In the whole water safety assessments which are based on water standard, health risk assessment only describes whether hazardous pollutants exceeded seriously. It doesn't directly reflect the effect of water on human health. This paper aims at how to quantify severity of pollutants in drinking water so that risk degree can be used directly to represent hazard to human health.

This paper takes Rain City District of Ya'an in Sichuan Province for example. According to the analysis of detection result for the 8 water sources, carcinogenic risk and non-carcinogenic risk of transnormal items in water are calculated and analyzed using health risk assessment model recommended by USEPA. Risk level of rural drinking water environment in research area, the primary-secondary of pollutants and the priority order of governance are also demonstrated in this paper, providing scientific foundation for drinking water risk management in research area.

\section{Material and Methods}

\subsection{Overview of the Study Area}

Rain City District of Ya'an locates in western edge of the basin where sits in the middle Qingyi River, with longitude of $102^{\circ} 51^{\prime} \mathrm{E}-103^{\circ} 12^{\prime} \mathrm{E}$ and latitude of $29^{\circ} 40^{\prime} \mathrm{N}$ $30^{\circ} 14^{\prime} \mathrm{N}$ and covering $1,066.99 \mathrm{~km}^{2}$. It locates in the northern slope of Erlang branch range which belongs to Qionglai Mountains, at 515.97-2,629.4m altitude. It belongs to middle-low mountain region that the west area is higher than east. The mountains occupied $91 \%$ of the whole region including $45 \%$ low mountains which altitude is less than $1,000 \mathrm{~m}, 46 \%$ middle mountains which altitude is more than $1,000 \mathrm{~m}$ and $9 \%$ flatland. In this area, the climate type belongs to subtropical humid monsoon climate except a few high mountain regions. The annual precipitation is $1,732 \mathrm{~mm}$. The maximum is $2,367.3 \mathrm{~mm}$ (in 1966) and the minimum is $1,204.2 \mathrm{~mm}$ (in 1974). The main rivers in this area are Qingyi River, Zhougong River, Longxi River, Fen River, Gaoqiang River, Yanchang River and Yanqiao River. The amount of their total length is $197.4 \mathrm{Km}$. The main runoff of these rivers is $580.5 \mathrm{~m}^{3} / \mathrm{s}$ and the amount of total runoff is 15.1 billion $\mathrm{m}^{3}$.

The population in this area is 320 thousand including 207.326 thousand in rural. The investigation in 2004 points out that unsafe rural drinking water affects 657.88 million people in this area. And 354.02 million people drink untreated surface water whose bacteriological index exceeds standard seriously. Besides, the untreated and seriously polluted groundwater affects 1,517 people and other drinking water affects 101.04 million people. It is urgent and essential to make health risk assessment actively and improve the rural drinking water conditions in this area.

\subsection{Samples Investigation}

8 water samples were collected in 2005 according to terrain, landform, geology, hydrology, water system, drinking water sources, distribution of waterborne infectious disease and types of water supply project. According to related standards of water quality detection methods, there are 21 indexes of these water samples which are detected, such as physics water quality indexes (color, turbidity, odor, visible material by bare eye), hydrochemistry index ( $\mathrm{PH}, \mathrm{COD}$, total hardness, total dissolved solids, chloride, sulfate), toxicological indexes ( $\mathrm{Fe}, \mathrm{Mn}$, fluoride, $\mathrm{As}, \mathrm{Hg}, \mathrm{Cd}, \mathrm{Cr}, \mathrm{Pb}$, nitrate), bacteriological index (total bacterial count, total coliform count. 6 hydrochemistry toxicological indexes need health risk assessment according to if the detected water quality indexes are harmful to human. And the 6 indexes are As, $\mathrm{Hg}, \mathrm{Cr}, \mathrm{Pb}, \mathrm{Cd}$ and fluoride.

The sampling sites and mainly water quality problems of rural drinking water safety in Rain City District of Ya'an can be seen in Figure 1.

The monitoring data of pollutants of rural drinking water in Rain City of Ya'an can be seen in Table 1 In the study area, the pollutants concentration scopes of the water sampling are as follows: As: $0.004 \mathrm{mg} / \mathrm{l}, \mathrm{Hg}$ : 0.001 $\mathrm{mg} / \mathrm{l}, \mathrm{Cr}^{6+}: 0.005 \sim 0.015 \mathrm{mg} / \mathrm{l}, \mathrm{Pb}: 0.01 \mathrm{mg} / \mathrm{l}, \mathrm{Cd}: 0.005$ $\mathrm{mg} / \mathrm{l}$, fluoride (F): $0.01 \sim 1.4 \mathrm{mg} / \mathrm{l}$. Compared with the Rural Surface Water Environment Quality Standard (GB3838-2002), each indicator achieves I III sort of standard except fluoride (F).

\subsection{Health Risk Assessment Models and Parameters}

There are many researches of dosage-reaction relation to human health risk assessment at present $[5,6,7]$, which are calculated from the basis of various investigation and experiment data. The first choice is the survey materials of human epidemiology, and the second one is the experiment materials of sensitive animal close to the mankind. In the light of the hazard effect by pollutants and a large number of research results from hazard substance (including the carcinogen and non-carcinogen) for several decades, the risk models that are applied to the human health hazard affected by different contaminations (including the drinking approach) may be established. These models include the carcinogenic risk model, the non-carcinogenic risk model and the total hazard risk model of health.

The carcinogenic risk model: 


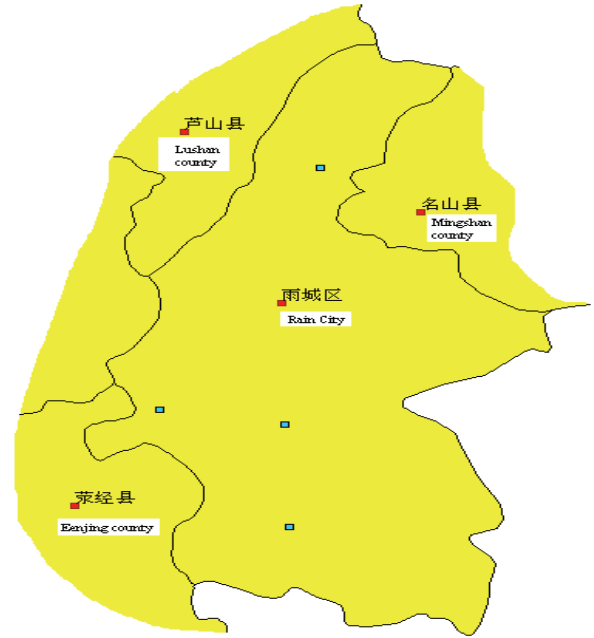

Sites distribution of fluoride exceeded

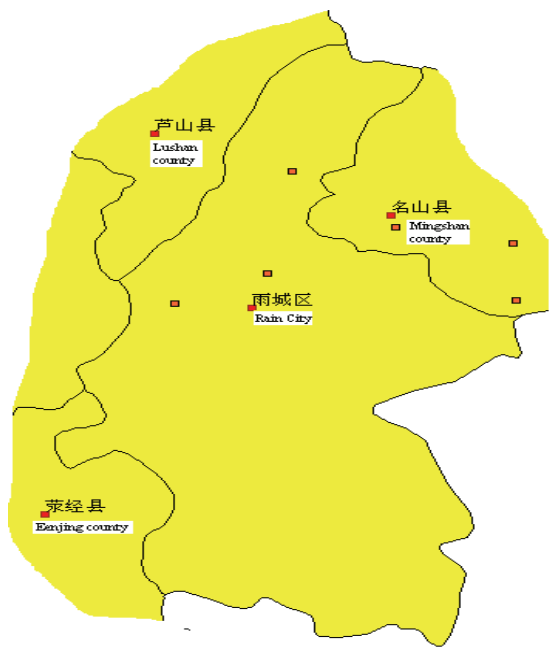

Sites distribution of water quality seriously polluted

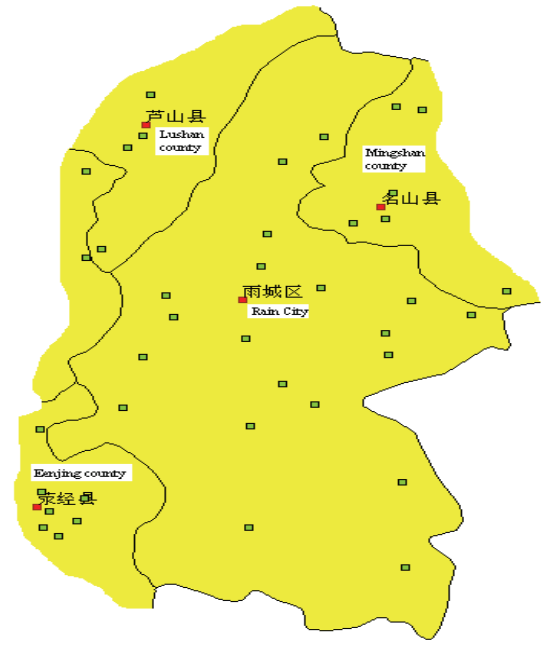

Sites distribution of poor water quality

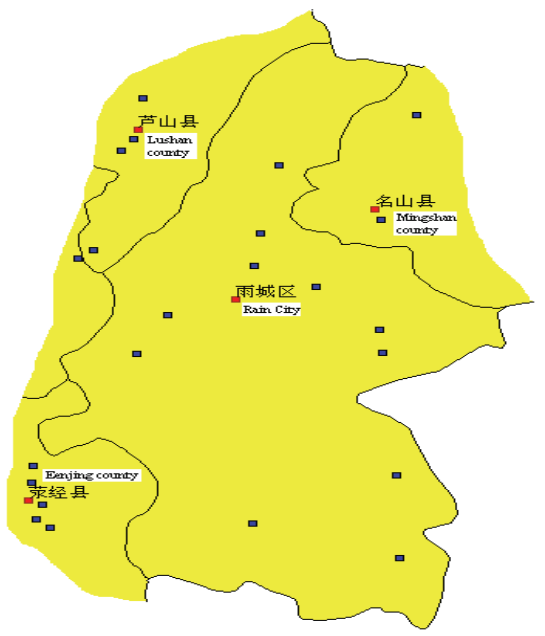

Sites distribution of bacteria exceeded

Figure 1. The map of water quality problems in Rain City District of Ya'an.

Table 1. Exposure concentrations of the sampling sites in Rain City of Ya'an（mg/l） .

\begin{tabular}{ccccccccc}
\hline Serial Number & Sample Sites & $\mathrm{As}$ & $\mathrm{Hg}$ & $\mathrm{Cr}^{6+}$ & $\mathrm{Pb}$ & $\mathrm{Cd}$ & fluoride(F) \\
\hline 1 & Fuping village & 0.004 & 0.001 & 0.05 & 0.01 & 0.005 & 0.1 \\
2 & Liujia village & 0.004 & 0.001 & 0.05 & 0.01 & 0.005 & 1.4 \\
3 & Kanpo village & 0.004 & 0.001 & 0.05 & 0.01 & 0.005 & 0.1 \\
4 & Liuliang village & 0.004 & 0.001 & 0.015 & 0.01 & 0.005 & 0.39 \\
5 & Pingshi village & 0.004 & 0.001 & 0.005 & 0.01 & 0.005 & 0.32 \\
6 & Liba village & 0.004 & 0.001 & 0.006 & 0.01 & 0.005 & 0.12 \\
7 & Zhanggou village & 0.004 & 0.001 & 0.005 & 0.01 & 0.005 & 0.16 \\
\hline
\end{tabular}




$$
\begin{gathered}
R^{c}=\sum_{i=1}^{k} R_{i}^{c} \\
R_{i}^{c}=\left[1-\exp \left(-D_{i} q_{i}\right)\right]
\end{gathered}
$$

where, $R_{i}^{c}$ is assigned the carcinogenic contamination $i$ to the average individual carcinogenesis annual risk by pathway-intake, $a^{-1} ; D_{i}$ is assigned the carcinogenic contamination $i$ to the daily average exposure dosage per unit weight by the pathway-intake, $\mathrm{mg} /(\mathrm{kg} \cdot \mathrm{d}) ; q_{i}$ is assigned the carcinogenic contamination $i$ to the carcinogenic by the pathway-intake, $\operatorname{mg}(\mathrm{kg} \cdot \mathrm{d}) ; 70$ is average span of human, a. The $D_{i}$ can be expressed:

$$
D_{i}=2.2 \times C_{i} / 70
$$

where, 2.2 is average daily intake from drinking water for an adult, $\mathrm{L} ; C_{i}$ is the concentration of carcinogenic contamination $i, \mathrm{mg} / \mathrm{L} ; 70$ is average weight of human, $\mathrm{kg}$ ).

The non-carcinogenic risk model:

$$
R_{i}^{n}=\left(D_{i} / R f D_{i}\right) \times 10^{-6} / 70
$$

where, $R_{i}^{n}$ is assigned the non-carcinogenic contamination $i$ to the average individual health hazard annual risk by pathway-intake, $a^{-1} ; D_{i}$ is assigned the non-carcinogenic contamination - to the daily exposure dosage per unit weight by pathway-intake, $\mathrm{mg} /(\mathrm{kg} \cdot \mathrm{d}) ; R f D_{i}$ is assigned the non-carcinogenic contamination $i$ to reference dosage, $\mathrm{mg} /(\mathrm{kg} \cdot \mathrm{d}) ; 70$ is average span of human, a.

Total risk model of water environment health assessment:

The cumulative effects of the toxic substances which damage the physical health of human include addition relation, cooperating relation and resisting relation. $\mathrm{Cu}-$ mulative effects analysis (CEA) is a very complicated and uncertainty work. To obtain reliable result, it is nec- essary to get enough successive historical and current observation data. At present, the developed countries are paying great attention to CEA, and also have carried out a lot of real researches. But the systematic theory and method have not formed.

The concentrations of toxic substances are very low in the daily drinking water source. It is assumed that the effect which each compound causes is independent and the relation among between cumulative effects of the toxic substances which damage the physical health of human is addition relation, but not cooperating relation or resisting relation. So the total water environmental health risk $\left(R_{h}\right)$ can be expressed as following:

$$
R_{h}=R^{c}+R^{n}
$$

Formula (5) is the total risk model of rural drinking water safety health assessment.

Health risk assessment parameters $[8,9,10]$ :

According to the taxonomy of the International Cancer Development Facility (IARC) and the World Health Organization (WHO) which is established through the comprehensive appraisal chemical substance carcinogenicity reliability level, the chemical substances in Group 1 or Group 2A are chemistry carcinogen. Their carcinogenicity assurance factors can be found in Table 2.

Regarding to the health risk appraisal resulting from the non-carcinogen, the reference dosage is an important parameter. According to the relevant data, the reference dosages are found and can be seen in Table 3 .

\section{Results and Discussion}

\subsection{Results}

According to health risk assessment models recommended by USEPA and the evaluation parameters, the average individual health hazard annual risk of the non-carcinogens and the average individual carcinogenesis annual risk of the chemical carcinogens through the drinking water in this district in 2005 can be calculated.

Table 2. Carcinogenicity intensity coefficient of chemical carcinogen $q_{i} \quad[\mathbf{m g} /(\mathrm{kg} \cdot \mathbf{d})]$.

\begin{tabular}{cccc}
\hline chemical carcinogen & $\mathrm{Cd}$ & $\mathrm{As}$ & $\mathrm{Cr}^{6+}$ \\
\hline$q_{\mathrm{i}}$ & 6.1 & 15 & 41 \\
\hline
\end{tabular}

Table 3. The reference doses of non-carcinogens $R f D_{i}[\mathrm{mg} /(\mathrm{kg} \cdot \mathrm{d})]$.

\begin{tabular}{cccc}
\hline Non-carcinogen & $\mathrm{Hg}$ & $\mathrm{Pb}$ & fluoride $(\mathrm{F})$ \\
\hline$R f D_{i}$ & $3.0 \times 10^{-4}$ & $1.4 \times 10^{-3}$ & $6.0 \times 10^{-2}$ \\
\hline
\end{tabular}




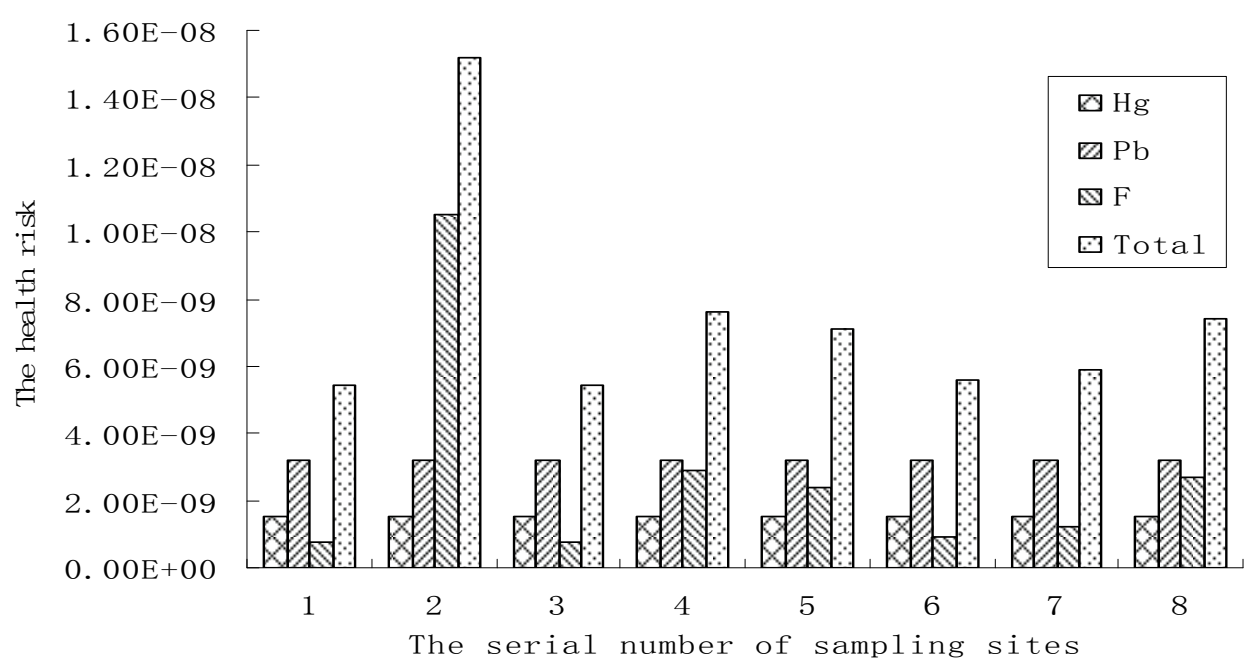

Figure 2. The average individual health hazard annual risk of the non-carcinogens.

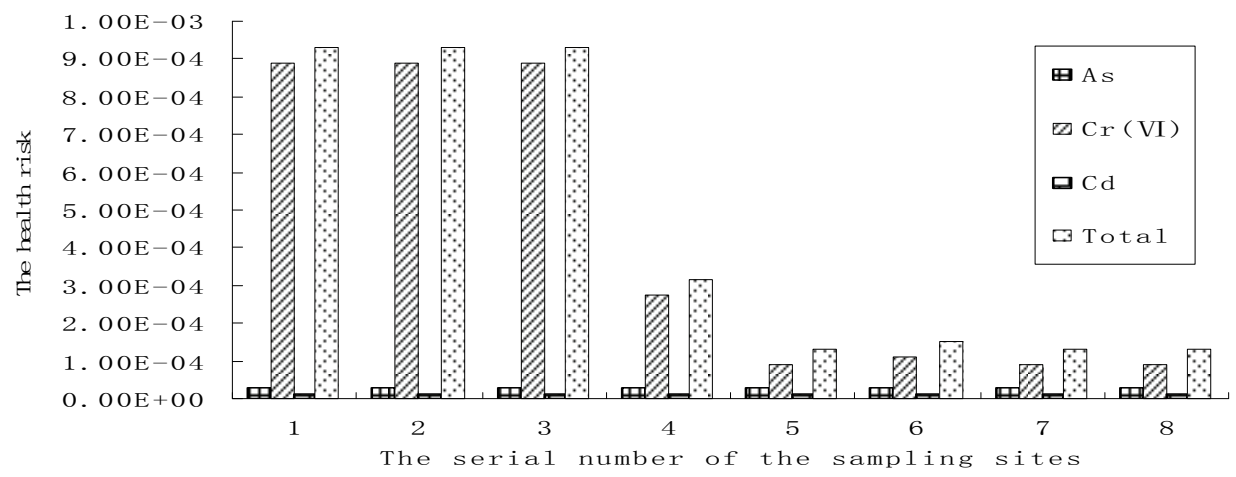

Figure 3. The average individual carcinogenesis annual risk of the carcinogens.

The average individual health hazard annual risk of the non-carcinogens can be seen in Figure 2. In the investigation area, the greatest risk value due to non-carcinogen pollutant is caused by fluoride $(\mathrm{F})$, achieving $1.05 \times 10^{-8} / \mathrm{a}$. The ranking of risk value due to non-carcinogen pollutant by drinking water is $\mathrm{Pb}>$ fluoride $(\mathrm{F})>\mathrm{Hg}$, within $\mathrm{Pb}$ accounting for $44.77 \%$, fluoride (F) accounting for $34.30 \%$ and $\mathrm{Hg}$ accounting for $20.92 \%$. The average risk values order of the 8 sampling points caused by the non-carcinogen pollutants is as follows: Number $2>$ Number $4>$ Number $8>$ Number $5>$ Number $7>$ Number $6>$ Number $3=$ Number 1 .

The average individual carcinogenesis annual risk can be seen in Figure 3. Among the three kinds of chemical carcinogens, the average individual carcinogenesis annual risk of $\mathrm{Cr}^{6+}$ is the greatest, achieving $8.91 \times 10^{-4} / \mathrm{a}$. The ranking of risk values due to chemical carcinogen by rural drinking water of $\mathrm{Ya}^{\prime}$ an is $\mathrm{Cr}^{6+}>\mathrm{As}>\mathrm{Cd}$, within $\mathrm{Cr}^{6+}$ accounting for $91.12 \%$, As accounting for $5.89 \%$ and $\mathrm{Cd}$ accounting for $3.00 \%$. The order of risk values of the 8 investigation sampling sites caused by the chemical carcinogen is as follows: Number $1=$ Number $2=$ Number $3>$ Number $4>$ Number $6>$ Number $5=$ Number $7=$ Number 8 .

\subsection{Discussion}

The level of human health hazard individual annual risk caused by non-carcinogens virulent chemical material concentrates in $10^{-8} \sim 10^{-10} / \mathrm{a}$. Namely, because of the drinking water's non-carcinogens pollutants, human health risk or the death population in each ten million people is less than one person. This indicates that the human health risk caused by the non-carcinogenicity chemical substances is slighter and will not be harmful to human health obviously. The level of human health individual annual risk caused by carcinogens virulent chemical substances concentrates in $10^{-4} \sim 10^{-5} / \mathrm{a}$. Namely, because of the drinking water's carcinogenic pollutants, the health dangers (or deaths) in each ten million are more than 100 or 1000 people. Thus, the health danger individual annual risk caused by carcinogenic toxic sub- 
stances is much bigger than one caused by total non-carcinogen toxic substances in the research area. The American Environmental Protection Bureau (EPA) carcinogenicity risk assessment guide points out that the risk is acceptable if the risk level is lower than $10^{-4} / \mathrm{a}$ in one year. The health danger individual annual risk resulting from each kind of pollutant of rural drinking water source in Ya'an is on this level. But it surpasses the acceptable maximum $\left(5 \times 10^{-5} / \mathrm{a}\right)$, which is recommended by International Commission on Radiological Protection (ICRP).

Thus, chemical carcinogens are primary and should be removed accordingly. The effective way of decreasing the health risk is to control and dispose the rural drinking water containing $\mathrm{Cr}(\mathrm{VI}), \mathrm{Pb}$ and fluoride $(\mathrm{F})$. The results can provide important information of the early warning for rural drinking water quality management.

\subsection{Risk Management}

\section{Enhance the conservation of water sources}

Technical measures: In order to ensure the drinking water quality, the drinking water source of Qingyi River should be protected according to the relational laws in Regulations of pollution control to the Drinking Water Source Conservation Areas, etc.

Construction contents: The conservation areas are determined and the signs are set. The point source pollution in conservation areas, such as rubbish, toilet, are removed. In conservation areas, the organic agriculture and water protection forest are developed to avoid non-point pollution caused by pesticide and fertilizer and to reduce the soil and water losses and preserve the water resources.

Construction standards: The water quality is improved and reaches the drinking water standard. The groundwater quality reaches standards of groundwater quality $(G B / T 14848)$ and the surface water quality reaches environmental quality standards of surface water (GB3838).

\section{Construction of drinking water supply}

The construction of drinking water supply contains water sources, facilities of water treatment, pipe network of water delivery and distribution, water quality detection and so on. The construction of each part should reach the requirements of relational regulations.

The selection and distribution of water sources: The exploration and demonstration of water source selection should be so deep and meticulous that can reduce the investment of water supply system and the cost of water. In addition, the exploration and demonstration should ensure that the technologies are feasible, operation and management are convenient and water supplying is safe and reliable. When there are more than two water sources to select, the different schemes should be compared according to heir water qualities, water volume, engineering investments, operation cost, constructions, managements and the conditions of healthy protection. Then, the best scheme is decided. The regional water resources allocation should be optimized well. The high quality water is priority as drinking water for daily life.

Engineering type selection: According to the local conditions of water source, water demand, landform and the residential area density and the engineering types are determined reasonably by comparing their technologies and investment.

Selections of water treatment measures: the following conventional water treatments are adopted to process the original water which reaches the standards of water source quality. The groundwater with good quality only needs disinfection treatment. If the original water's permanent turbidity is less than 20NTU and the instant one is less than $60 \mathrm{NTU}$, the technology of slow filtering with disinfection or contact filtration with disinfection will be adopted. In addition, the ultrafiltration membrane technology can be taken to process the original water. If the original water's permanent turbidity is less than $500 \mathrm{NTU}$ and the instant one is less than 1000NTU, the technology of coagulation sedimentation (or clarification) and filtration with the disinfection will be adopted. If the original water's sediment concentration changes greatly or its turbidity is usually more than 500NTU, the facilities of pre-precipitation and rough filtration or infiltration will be added before the conventional water treatment technology.

If there is no qualified water source indeed, the following special water treatment measures should be adopted. For brackish water desalination, the treatment measures, such as electrodialysis, reverse osmosis, electric absorption should be adopted. For reducing the fluoride in high fluoride water, the treatment measures, such as medium adsorption, electrodialysis, reverse osmosis, electric absorption should be adopted. For the treatment of micro-polluted water, the enhanced conventional water treatment technology should be adopted. In addition, the following measures added into the conventional water treatment technology are adopted, such as air floatation technology, biological pretreatment, chemical pre-oxidation treatment, activated carbon treatment, the ozone activated carbon advanced treatment.

Selection of material and equipment: Comparing the technology and investment, the material and equipment in water supply engineering are determined according to the concrete engineering situation. The material and equipment should have reliable performance and reach the relational national standards and requirements of hygienic and safety. The products which are corrosion resistant, aging resistant, energy-saving, water-saving and good for environmental protection should be given priority to be used. 


\section{Water quality monitoring}

According to the requirements of The Drinking Water Health Standards (GB5749), laboratory has been built which is equipped with the appropriate water quality monitoring equipment to monitor the water quality coming from the water resources, the waterworks and peripheral water of pipe network. For the water supply project in smaller scale, automatic test equipment or simple testing equipment should be adopted or can be also tested by the entrusted with drinking water quality testing units.

Establishment and effective implementation for water safety emergency mechanism

For the study of the emergency measures to unexpected events water safety, the comprehensive emergency preparedness should be formulated from the legal system, institutional settings, the application of information technology, multi-sector participation, professional research, capital protection, etc. The main contents of the rural water safety emergency mechanism include as follows: forecasting the large-scale flood and drought disaster and possible rural water safety emergency events based on the regional climate and water resources status; designing the corresponding emergency preparedness according to rural water safety emergency calculation water quantity; setting up a special inter-departmental water safety emergency control and implementation agencies to enhance reaction speed and achieve the "emergency" requirement really.

\section{Conclusions}

Combining the rural drinking water quality with public health hazards, this paper quantitatively analyzes the degree of water environmental pollution on public health hazards and obtains the synthesized results of the water environmental quality based on the health risk calculated results. And it also determines the primary-secondary water pollutions, gives the control priority, and provides a scientific basis and decision-making objects of the environmental risk management.

In the study area, the mainly problems of the water environmental health risks are as follows: rural water source pollutant risk, the outburst water source pollutant risk, simple supply structures and the weak ability to resist risks, unexpected geological disasters increasing the risk of the rural water supply system, water treatment risk, water sources health risk of surrounding areas, etc. The calculated results show that the greatest health risk for individual person per year is caused by $\mathrm{Cr}(\mathrm{VI})$. The health risk of carcinogens is much higher than that of non-carcinogens. The greatest risk value due to non-carcinogen pollutants is caused by fluoride (F), achieving $1.05 \times 10^{-8} / \mathrm{a}$. The ranking of risk values due to non-car- cinogen pollutants by drinking water is $\mathrm{Pb}>$ fluoride (F) $>\mathrm{Hg}$, within $\mathrm{Pb}$ accounting for $44.77 \%$, fluoride (F) accounting for $34.30 \%$ and $\mathrm{Hg}$ accounting for $20.92 \%$. The average individual carcinogenesis annual risk of $\mathrm{Cr}(\mathrm{VI})$ is the greatest, achieving $8.91 \times 10^{-4} / \mathrm{a}$. The ranking of risk values due to chemical carcinogen by rural drinking water of $\mathrm{Ya}^{\prime}$ an is $\mathrm{Cr}^{6+}>\mathrm{As}>\mathrm{Cd}$, within $\mathrm{Cr}^{6+}$ accounting for $91.12 \%$, As accounting for $5.89 \%$ and $\mathrm{Cd}$ accounting for $3.00 \%$. Based on this, this study pointed out that the effective way of decreasing the health risk is to control and dispose the rural drinking water containing $\mathrm{Cr}(\mathrm{VI}), \mathrm{Pb}$ and fluoride $(\mathrm{F})$. The results can provide important information of the early warning for rural drinking water quality management.

In the study area, the mainly control measures of the water environmental health risk are as follows: conserving the water resources, constructing supply water project, monitoring water quality, investigating and constructing emergency water sources, establishing and implementing of water safety emergency mechanism effectively.

The rural water source water quality health risk assessment shows the relationship between water quality and human health. It can provide much more scientific information for the management and protection of rural water sources to apply this method to evaluate the water quality safety of rural water source and detect the relationship between the source water quality and human health.

This study has uncertainty to some extent and mainly showing as follows. On one hand, following the risk assessment method of the effect of drinking water pollutants on human used by EPA, the exposure way just takes average drinking intake into consideration which excludes other toxic substances and their routes, for instance, inhaling by dermal touch and the form of steam and dieting. Actually, the exposure risk of pollutants is underestimated. On the other hand, the exposure risk by drinking is also closely bound up with residence time of water in domestic pipe network, consumer's life style, consuming habit and career. So more complicated exposure assessment method is needed to get the average exposure dose by consumer touch, the daily distribution of pollutants exposure dose and the main exposure chance that individual is affected by pollutants. Therefore, this study on the pollutants exposure risk in water is elementary which need to be developed further in future [11].

\section{Acknowledgements}

This study is financed jointly by Sichuan Agricultural University youth science and technology innovation fund (00530300) and Sichuan Agricultural University introduces the talented person fund (00530301). 


\section{References}

[1] F. Wang, "Water pollution, unneglectable point," Ecological Economy, No. 7, pp. 142-145, July, 2006.

[2] M. Luo, "Analysis of the relationship between drinking water and health," Guide of Chinese Medicine, Vol. 6, No. 14, pp. 160-161, July 2008.

[3] F. Ni, et al., "Drinking water safety decision support system for rural areas in Ya'an city of China," in Proceedings of the 5th International Conference on Urban Watershed Management \& Mountain River Protection and Development, Vol. 2, Sichuan University Press, pp. 669-677, April 3-5, 2007.

[4] D. Wang, et al., "Applications of the health hazard assessment for the environmental quality," Environmental Pollution \& Control, No. 5, pp. 91-92, July 1995.

[5] U. S. National Research Council, "Risk assessment in the federal government: Managing the process," National Academy Press, Washington, D. C., 1983.
[6] USEPA, "The risk assessment guidelines of 1986 ," EPA Report, No. EPA/600/18-87/045, Washington, D. C..

[7] "Superfund Public Health Evaluation Manual," USEPA/ 540/186060, EPA.

[8] J. Gao, L. Zhang, S. Huang, et al. "Preliminary health risk assessment of heavy metals in drinking waters in Beijing," Environmental Science, Vol. 25, No. 2, pp. 47-50, 2004.

[9] G. Zeng, L. Zhuo, Z. Zhong, et al., “Assessment models for water environmental health risk analysis," Advances in Water Science, No. 3, pp. 212-217, September 1998.

[10] H. Luo, R. Xu, X. Liu, et al., "The system design of water environmental health risk assessment in river," in Proceedings of the 5th International Conference on Urban Watershed Management \& Mountain River Protection and Development, Vol. 1, Sichuan University Press, pp. 189-198, April 3-5, 2007.

[11] H. Chen, F. Liu, et al., "Health-based risk assessment of contaminated sites: A case study," Earth Science Frontiers, Vol. 13, No. 1, pp. 230-235, 2006. 